\title{
La gestión de la comunicación digital en las cooperativas españolas
}

\section{Pedro Pablo Marín Dueñas, Diego Gómez Carmona}

RESUMEN: El futuro de las empresas, y las cooperativas en particular, por su contribución al progreso económico y social de las comunidades en las que desarrollan su actividad enfrentadas a una gran competencia y a un entorno muy cambiante, va a depender en gran medida de su capacidad de gestión estratégica en general y, más específicamente, de su capacidad para gestionar su comunicación. Ante la importancia creciente que la comunicación en general y la comunicación digital en particular tiene para el desarrollo de las cooperativas, es fundamental llevar a cabo investigaciones que profundicen en la gestión que éstas hacen de la misma. Dada la relevancia que para la economía tienen estas organizaciones, este trabajo se plantea como objetivo general analizar la gestión que de la comunicación digital hacen las cooperativas españolas, a través de la metodología cuantitativa de la encuesta a una muestra de 338 cooperativas. De los resultados se desprende que, si bien la comunicación es una herramienta clave, esto no se ve reflejado ni en la inversión ni en el desarrollo de planes estratégicos por parte de las cooperativas, situándose en un nivel medio-bajo en cuanto a la gestión que de la comunicación digital hacen estas organizaciones.

PALABRAS CLAVE: Comunicación empresarial, Comunicación digital, Social Media Marketing, Gestión comunicacional, web 2.0.

CLAVES ECONLIT: D83, M30, M31, M38, Q13.

Cómo citar este artículo/How to cite this article: MARÍN, P.P. \& GÓMEZ, D. (2021): "La gestión de la comunicación digital en las cooperativas españolas", CIRIEC-España, Revista de Economía Pública, Social y Cooperativa, 101, 193-225. DOI: 10.7203/CIRIEC-E.101.17638.

Correspondencia: Pedro Pablo Marín Dueñas, Universidad de Cádiz, pablo.marin@uca.es, 0RCID: 0000-0001-8692-1174; Diego Gómez Carmona, Universidad de Cádiz, diego.gomez@uca.es, ORCID: 0000-0002-0146-5956. 


\section{Expanded abstract}

\section{Management of digital communication in spanish cooperatives}

Today, communication has become an indispensable condition for achieving a favourable position in society and business success. The Internet has marked a before and after in developing marketing and communication strategies that organisations implement to relate with the population. The increase in the use of New Technologies Information and Communication (NTIC) by the population contributes to increasing the effectiveness of companies' online communication tools, allowing a bidirectional relationship with consumers and enhancing a better relationship between the organisation and its target audience. Cooperatives, which, even though they are social economy organisations, are ultimately companies and as such depend on the sale of products and services for their development, cannot and should not ignore this new reality, which imposes new forms, different from those used until now and in which the role between sender and receiver is exchanged.

Given the importance that Spanish cooperatives have for the development of local economies and their social relevance for the environment in which they are integrated (Monzón and Chaves, 2017; Chaves, Monzón and Zaragoza, 2013; Puentes and Velasco, 2009), this research on the management of digital communication by cooperatives is necessary. The purpose is to analyse the importance that cooperatives give to the development of online communication strategies. Specifically, the general objective of the study is to analyse how cooperatives manage their digital communication. It is articulated in a series of specific objectives that complement it and serve as a basis for the design of the research and the choice of methodological tools to be implemented during the development of the same.

- To measure the degree of importance that cooperatives attach to communication.

- To analyse whether cooperatives plan their digital communication.

- $\quad$ 0.E.3. Find out who manages the digital communication of the cooperatives.

- O.E.4. Determine the level of investment in digital communication by the cooperatives.

- 0.E.5. To analyse how cooperatives manage digital communication.

The work used an online survey based on a structured questionnaire. This methodological instrument will allow the proposed objectives to be achieved. Self-reporting consists of obtaining observable data on variables of interest from the population under study in an orderly and systematic way.

This quantitative tool is one of the best known and one of the most complete of those used by communication researchers. From a scientific perspective, it is undoubtedly a valuable instrument for understanding social and business reality. In this sense, it is widely used in social science research. 
The variables studied and measured were:

- Importance of communication

- Level of investment

- Communication planning

- Assumption of tasks

- Definition of objectives

- Strategies

- Presence in Social media

- Social media followers

- Implementation of actions.

The final questionnaire was implemented through the Google Forms tool. The final sample, made up of 338 cooperatives from all over Spain, was selected through non-probabilistic convenience sampling.

The results suggest that those cooperatives that implement adequate online communication management will have a particular advantage and will be better positioned to compete in the market.

Although cooperatives allocate few economic resources to online communication, it is found that the higher the percentage of investment in communication, the more importance cooperatives attach to communication. Moreover, their management from a planned and strategic perspective is insufficient. In this sense, the cooperatives that consider this activity to be very relevant have more plans of this type.

The findings show that it is not the cooperatives with the largest number of employees or those operating in the international market that attaches most importance to communication. Although cooperatives tend to increase the importance of communication as the number of employees grows, it seems that this pattern slows down in those with between 50 and 249 workers and more than 500 employees.

From a positive point of view, it should be understood that the communication objectives are considered to incorporate rather than commercial terms, and improving the image, achieving notoriety and building customer loyalty stand out among the objectives of these companies, above other more market-oriented objectives such as promoting and selling products and services. In this sense, one shortcoming has to do with internal communication. Due to their eminently social and democratic nature, these organisations are a key element in which cooperative members do not set their communication objectives in terms of internal communication.

The cooperatives choose to promote the web as an information portal ahead of more interactive strategies in line with web 2.0, especially social media, about the development of digital communication strategies.

Finally, neither do the cooperatives studied develop critical actions in the management of digital communication, such as measuring the return on investment or studying non-economic KPIs, which are fundamental when analysing the strategies being developed. 
For all these reasons, it can be stated that the cooperatives analysed are at a medium-low level in terms of their digital communication management. Lack of investment and planning, preference for the web over social media or paid advertising and lack of measurement allow us to affirm that the cooperatives should boost their digital communication much more and promote it through investment and strategic plans.

Given these results, things have not changed much and currently; cooperatives still do not have a strategic vision of their (digital) communication, being scarce the resources they devote to it both in terms of planning and investment, which results in low visibility of these organisations within society to help their development and growth.

There is little research that has tried to analyse the digital strategies developed by cooperatives to our knowledge. This work provides information from a large part of the target population, so the findings are robust and generalisable. The study results highlight the reality of Spanish cooperatives concerning their communication strategies and their current shortcomings.

Keywords: Business communication, Digital communication, Social Media Marketing, Communication management, web 2.0. 


\section{Introducción}

Todas las organizaciones, con independencia de su forma jurídica, tamaño, productos o servicios ofrecidos o situación geográfica, deben comunicarse para sobrevivir (Stanton, 1989). Hoy día, la comunicación se ha convertido en condición indispensable para conseguir una posición favorable en la sociedad y lograr el éxito empresarial. El futuro de cualquier compañía, y el de las cooperativas en particular, organizaciones que basan su funcionamiento en el principio de la democracia participativa y que contribuyen de manera efectiva al progreso económico y social de las comunidades en las que desarrollan su actividad (Muñoz y Tirado, 2014), enfrentadas a una gran competencia y a un entorno muy cambiante, va a depender en gran medida de su capacidad de gestión estratégica en general y, más específicamente, de cómo planifiquen su comunicación.

Dicha gestión ha estado vinculada de manera directa al desarrollo de los medios de comunicación de masas (Jivkova, Requeijo y Padilla, 2017) y ha ido evolucionando de forma paralela a como lo ha hecho la sociedad y la tecnología, para conseguir alinear los intereses de las organizaciones en el contexto en el que éstas desarrollan su actividad. Cada tiempo ha estado influenciado por un medio y si en los comienzos del siglo XX fue la prensa escrita, posteriormente la radio y ya a mediados de siglo la televisión, hoy día es Internet la que marca un antes y un después en el desarrollo de las estrategias de marketing y comunicación que las organizaciones implementan para relacionarse con la población.

De hecho, para Canals (2001) la aparición de Internet y la revolución que la misma ha supuesto para las empresas es comparable a las revoluciones industriales que se han desarrollado a lo largo de la historia de la humanidad.

La primera revolución industrial supuso una transformación y mejora en la producción de bienes. La segunda revolución industrial añadió a aquella transformación un cambio radical en el transporte y, eventualmente, en las formas de distribución. La revolución de Internet está suponiendo una reconfiguración de las relaciones empresas-clientes-proveedores y, por tanto, exige un cambio en la estrategia y la organización de las empresas

(Canals, 2001: 61)

Hoy día, en esta época de convulsiones y cambios, ese desarrollo de Internet ha tenido un enorme impacto en los modelos de gestión de la comunicación. El aumento en la utilización de las Nuevas Tecnologías de la Información y la Comunicación (NTICS) por parte de la población contribuye a incrementar la eficacia de las herramientas de comunicación online usadas por las organizaciones, permitiendo una relación bidireccional con los consumidores y potenciando una mejor relación entre la organización y su público objetivo. Las cooperativas, que aún siendo organizaciones de la economía social, en definitiva son empresas y como tales dependen de la venta de productos y servicios para su desarrollo, no pueden, ni deben, ignorar esta nueva realidad, que impone nuevas formas, distintas a las utilizadas hasta ahora y en las que el papel entre emisor y receptor se intercambia. Internet ha sacudido los cimientos de las em- 
presas, reorientando incluso algunos principios de la estrategia empresarial (De Chernatony, 2001).

Nace entonces una nueva forma de comunicación, la digital, gracias entre otras cosas al mayor acceso que la población tiene a Internet y, sobre todo, a las redes sociales (Pérez y Nicasio, 2015). Tal y como apuntan Zugasti y Sabés (2015), a las páginas webs tradicionales y a los blogs, como primeros exponentes de la comunicación digital, se han añadido las redes sociales, basadas en el diálogo y la participación, posibilitando la aparición de nuevos escenarios en el terreno de la comunicación organizacional. Las reglas del juego han cambiado (Rodríguez y Ureña, 2011), ahora la clave está en la conversación y los social media se configuran como un canal idóneo para conectar con los consumidores, obviando los medios tradicionales y permitiendo una comunicación instantánea. El efecto que este medio ha tenido en el campo de la comunicación empresarial está fuera de toda duda, modificando las estrategias comunicativas de las organizaciones (Marín, Lasso de la Vega y Mier-Terán, 2015; Castelló y Montserrat, 2012) y situándose como un medio de comunicación estratégico (Capriotti y Zeler, 2020; Congosto, 2015; Castelló, 2010). Organizaciones de todo tipo, independientemente de su tamaño, estructura social o forma jurídica, se han trasladado desde hace una década al espacio digital encontrando un nuevo canal para la difusión de sus mensajes (Criado, Martínez y Silván, 2012) complementario a los medios tradicionales como la radio y la televisión.

Así, ante la importancia cada mayor que la comunicación digital está tomando para la gestión comunicativa de las organizaciones, se hace más necesario que nunca llevar a cabo estudios que analicen el uso que las instituciones hacen de la misma, de cara a detectar posibles carencias y errores y ofrecer posibles soluciones. Pero, a pesar del poderoso instrumento que Internet proporciona a las organizaciones cooperativas (Cristobal, Montegut y Daries, 2017), son escasas las investigaciones que se han ocupado de analizar el impacto de las NTICs en las organizaciones de la economía social y en cómo desarrollan esta comunicación digital. (Campos y Navarro, 2017). El desarrollo del marketing y la comunicación constituyen, como apunta Sá (2012: 202), "una oportunidad que la gestión de las organizaciones de la economía social está obligada a considerar, especialmente en estos tiempos que la globalización de mercado liberal mercantil se pretende imponer como modelo único" y como uno de los factores puede contribuir al éxito de las cooperativas (Sanchis, Campos y Mohedano, 2015).

Dada la importancia que las cooperativas españolas tienen para el desarrollo de las economías locales y por la relevancia social que las mismas tienen para el entorno en el que se integran (Monzón y Chaves, 2017; Chaves, Monzón y Zaragoza, 2013; Puentes y Velasco, 2009), se hace necesaria esta investigación sobre la gestión de la comunicación digital por parte de las cooperativas. El objetivo es analizar si éstas le conceden a esta herramienta la importancia que se merece y le prestan atención, desarrollando estrategias de comunicación a través de los canales online. 


\section{Objetivos}

Este trabajo tiene como objetivo general analizar como las cooperativas gestionan su comunicación digital. El mismo se articula en una serie de objetivos específicos que lo complementan y que servirán de fundamento para el diseño de la investigación y la elección de las herramientas metodológicas a implementar durante el desarrollo de la misma.

- $\quad$ 0.E.1. Medir el grado de importancia que las cooperativas conceden a la comunicación

- 0.E.2. Analizar si las cooperativas planifican su comunicación digital

- $\quad$ 0.E.3. Conocer quién gestiona la comunicación digital de las cooperativas

- O.E.4. Determinar el nivel de inversión en comunicación digital por parte de las cooperativas

- O.E.5. Analizar cómo gestionan la comunicación digital las cooperativas

\section{Un cambio de paradigma para la comunicación de las organizaciones: Internet}

Son muchos los autores que consideran que Internet se ha convertido en una herramienta esencial para la comunicación de las organizaciones (Capriotti y Zeler, 2020; Stelzner, 2019; Marín y Lasso de la Vega, 2017; Chung, Andreev, Benyouncef, Duane y 0’Reilly, 2017; Lee, 2016; Congosto, 2015; Castelló, del Pino y Ramos, 2014; Sánchez y Paniagua, 2013; García, 2012; Almansa, 2011). Grandes, medianas y pequeñas empresas, organizaciones del tercer sector y de la economía social, partidos políticos...entidades de cualquier tipo, en definitiva, han incorporado en sus estrategias comunicativas los diferentes canales que ofrece Internet y lo han hecho de manera progresiva, comenzando por las páginas Web tradicionales y los blogs para luego implementar el uso de las redes sociales en sus planes. Éstas se convierten, en la actualidad, en un instrumento muy eficaz dentro de las herramientas que utilizan para trasladar sus mensajes a la población, hasta el punto que ya no se puede hablar de planificación de la comunicación sin el uso de la web 2.0 y las redes sociales.

Si la comunicación de los individuos se transforma, también la comunicación de las organizaciones se modifica. No se trata, como se hacía hasta ahora, de gestionar para los públicos, sino de gestionar la comunicación tal y como los públicos se comunican. Lo importante ya no es comunicar pensando en el público, sino siendo público

(Túñez, Costa y Míguez, 2018: 922) 
Dada la actual estructura competitiva del mercado, las compañías necesitan de una adaptación a las nuevas tecnologías y la llegada de Internet ha puesto al alcance de las mismas medio para poner en valor sus ventajas y fortalezas, posibilitando que puedan superar las trabas que los mercados les imponen y permitiéndoles comunicarse e interactuar con sus públicos de interés.

"El impacto de Internet en el mundo de la empresa va más allá de la oferta de nuevos productos o servicios para convertirse en un tipo de tecnología que permite la creación de nuevos conceptos de negocio" (Canals, 2001: 64) y que, además, "ha revolucionado las formas de comunicación entre empresas y públicos" (García, 2012: 140). Este hecho es clave en el desarrollo actual del marketing ya que, a diferencia de las herramientas clásicas de comunicación, Internet añade nuevas posibilidades comunicativas: permite segmentar la campaña en función de los diferentes perfiles de los públicos, lo que supone mayor efectividad de la comunicación fomenta la bidireccionalidad, ofreciendo la posibilidad de interactuar de forma rápida y fácil, ofrece extensa información sobre las organizaciones a públicos amplios y dispersos y permite trabajar en tiempo real (Seitel, 2002).

Tal y como explican Zugasti y Sabés (2015) ahora el emisor tiene la posibilidad de enviar sus mensajes a un gran número de destinatarios a un mismo tiempo a través de Internet, lo que supone una ruptura con el sistema tradicional de comunicación lineal. En la actualidad cualquier individuo puede ser receptor y emisor a la vez o reemisor, lo que obliga a las organizaciones a adaptarse a la comunicación 2.0 modificando su actitud para poder entablar diálogo (Túñez, Martínez y Abejón, 2010).

Puede, por tanto, afirmarse que Internet y las redes sociales han introducido nuevas posibilidades para las organizaciones, cambiando y redefiniendo la relación entre éstas y los consumidores y trasladando la actividad comunicativa a la red (Zerfass, Moreno, Tench, Verčič y Verhoeven, 2017; Moreno, Molleda, Athaydes, Suárez, Herrera y Álvarez, 2017; Cotarelo, 2013).

Gracias a todos los avances que ha propiciado el desarrollo de la sociedad web, los mass-media ya no son el único canal para llegar a los públicos. Esta nueva forma de interaccionar de forma directa a través de Internet es, a día de hoy, la preferida por la ciudadanía; lo que queda reflejado en el creciente uso de redes sociales como Facebook, Instagram, Twitter, Linkedin, entre otras, por parte de la población. Y este evidente desarrollo ha supuesto un punto de inflexión para las empresas en la manera de comunicar con sus públicos (Marín y Lasso de la Vega, 2017). Internet ofrece un amplio abanico de posibilidades para que organizaciones de cualquier tipo envíen sus mensajes de una manera más efectiva que con los denominados medios tradicionales y se configura como nexo de unión entre las marcas y sus consumidores, con quienes empiezan a establecer conversaciones y relaciones más directas, con el fin de escuchar y entender al mismo (Bort, García y Martín, 2011). Como apuntan Pérez y Luque (2018: 257) "los social media han cambiado la forma de comprar, de pensar y de actuar de los consumidores" quienes tienen un papel activo en el proceso de comunicación con empresas y marcas, situándose en el centro de las estrategias de marketing y comunicación (Martínez, Segarra y Montserrat, 2018). 
La aparición de este nuevo consumidor está modificando el paradigma tradicional del marketing y surge, de esta manera, el denominado social media marketing o marketing digital, una nueva forma de hacer comunicación que permite desarrollar las estrategias comunicativas de las organizaciones a través del medio online: la web, las redes sociales, el email marketing, el blog y la publicidad online son los principales mecanismos con los que cuentan las empresas para llegar a sus consumidores ayudando a las empresas a lograr una mayor visibilidad, incrementando así sus beneficios, a llegar a nuevos mercados, a mejorar sus servicios al cliente, a transferir sus productos/servicios de una forma más eficiente, a trasladar su identidad a la sociedad, favoreciendo la consecución de una imagen positiva. Así, y tal y como apuntan diversos estudios (Moreno, Molleda, Álvarez, Herrera, Athaydes \& Suárez, 2019; Wright \& Hinson, 2017; Moreno, Molleda, Althaydes y Suárez, 2015), Internet ha modificado la manera en que las organizaciones se comunican con sus públicos, y los profesionales de marketing muestran su preferencia por los canales online para establecer relaciones con sus stakeholders.

\section{La importancia de la comunicación digital para las organizaciones}

La Web 2.0 no solo permite comprar y vender productos y servicios por la red, sino que implica nuevas estrategias de comunicación para interactuar con los públicos. El efecto que ésta ha causado en el mundo de la comunicación empresarial está fuera de toda duda cambiando las estrategias comunicativas de muchas organizaciones. Y otras, que antes no contaban con ella, empiezan a preocuparse por las mismas. La importancia que cobra el nuevo medio tiene que hacer que directivos, gerentes, propietarios y personal de marketing y comunicación, se preocupen por implementar acciones comunicativas a través del medio online

La necesidad de diferenciar la empresa hace necesaria una estrategia de imagen y comunicación en la Web 2.0 que ponga de manifiesto los esfuerzos de las empresas por integrar a sus públicos en la misma. Las compañías necesitan tener tanto páginas Web como perfiles en redes sociales que sean eficaces a la hora de permitir la comunicación con esos públicos. Y esta importancia ha llevado a la proliferación, lenta pero constante, de empresas que cuentan con planes de comunicación digital o, cuanto menos, desarrollan acciones en el medio online.

Debe tenerse en cuenta, que, en general, la empresa española, por sus características particulares (el 98\% son micro, pequeña o medianas empresas) no contemplaba la necesidad de la inversión en comunicación. Una percepción que ha cambiado de manera casi radical y en muy poco tiempo, con la consolidación del medio Internet como el más importante y rentable recurso de comunicación persuasiva, informativa y de ocio, que debe ser entendido desde esta vertiente tripartita con el fin de operar una gestión comunicativa eficaz y rentable para las compañías, ya que no sólo se trata de aparecer en la red de redes, sino que debe tratarse de una aparición prefijada y controlada, con el objeto de minimizar costes y recursos y de maximizar beneficios. 
La llegada de Internet ha hecho que muchas empresas modifiquen sus estrategias de comunicación y de marca e incluso, aquellas que no se preocupaban y careciesen de ella, empiezan a preocuparse por las mismas (García y Castillo, 2010). Esta expansión ha supuesto la creciente capacidad para las empresas de expandir su actividad, permitiendo una relación más personalizada con sus públicos a través de la comunicación digital.

La comunicación digital, en definitiva, se debe configurar como un instrumento básico para las organizaciones ya que, entre otras, proporciona las siguientes oportunidades y beneficios:

- Permite alcanzar ventajas competitivas

- Facilita realizar transacciones en tiempo real

- Hace que el negocio sea más visible y competitivo

- Influye en la imagen y credibilidad del negocio

- Permite la comunicación bidireccional, posibilidad de hablar directamente con los públicos

- Facilita el acceso al público objetivo

- Mejora la competitividad organizacional

- Reduce costes: tanto para la organización en sus procesos de producción como para los públicos en sus procesos de búsqueda de información

- Elimina los intermediarios

- Elimina las restricciones geográficas: las empresas están a un solo click. Permiten dar a conocer a la organización a públicos que pueden estar en sitios muy lejanos

- Permite aumentar el número de clientes

- Hace más eficaz la comunicación, permitiendo desarrollar y construir relaciones más directas, personalizadas y a largo plazo

- Promociona los productos y servicios facilitando la consecución de los objetivos de Marketing

- Desarrolla las Relaciones Públicas

- Permite dirigirse a cada consumidor con un mensaje personalizado

- Facilita la comparación con las webs de una amplia variedad de organizaciones

- Es el lugar más económico para publicitarse

- Permite participar en redes sociales

- Actualización a diario de la información: se pueden añadir productos, cambiar textos, incluir fotografías o eliminar cualquier aspecto

- Alta capacidad de afinidad

- Alto poder de microsegmentación

- Mediciones postcampaña

- Fideliza, permitiendo mantener informados a los públicos constantemente

- Mejora el branding y permite el conocimiento y la memorabilidad gracias a la presencia continua del nombre y la marca

Y en el caso concreto del uso de las redes sociales, Carreras (2011) identifica los siguientes beneficios para las organizaciones: 
- Posibilidad de hablar directamente con nuestros públicos

- Monitorizar la marca en tiempo real

- Escuchar y analizar conversaciones en tiempo real

- Responder con celeridad

- Establecer conversaciones

- Participar en redes sociales y aportar valor real

- Distribuir nuestro contenido

- Construir relaciones con nuestros públicos (medios, bloggers, empleados, inversores, seguidores, clientes, etc.)

- Identificar y conectar con influencers y 'brand evangelists'

- Integrar la tecnología y sus posibilidades dentro de nuestros planes y acciones

- Construir comunidad

- Captar tendencias en comunicación

Como señala Castelló (2010) Internet se configura como el medio idóneo para personalizar el mensaje y facilitar la interacción entre las empresas y sus públicos, cumpliendo las expectativas de éstos, por lo que las empresas deberían integrar a la comunicación digital en sus estrategias comunicativas.

\section{La comunicación en las empresas de la economía social: el caso de las cooperativas}

Las organizaciones de la economía social poseen una naturaleza y unos valores inspiradores que los diferencian del resto de empresas y surgen en el mercado con "la finalidad de crear riqueza, generar trabajo o de resolver problemas sociales" (Cabra de Luna, 2003, p. 174). Si bien, desde una perspectiva económica, funcionan como una empresa tradicional (Herranz de la Casa, 2004) no es menos cierto que tienen unos objetivos que van más allá de los puramente cuantitativos o comerciales. En el caso concreto de las cooperativas, Losada y Maruny (1981) ya apuntaban a que el trato que estas organizaciones dan a sus clientes no debe limitarse a lo puramente comercial, sino que debe tener un trasfondo social, que satisfaga al comprador de la mejor manera posible, por lo que la comunicación debe ser una herramienta fundamental en la gestión de estas entidades o, cuanto menos, la importancia que se le conceda debería ser equiparable a la que cualquier organización le da a la misma.

Tal y como apuntan Bayón, Del Castillo y Arteta

En realidad, toda empresa tiene el deber de comunicar. Se lo debe a sus muchos públicos y a sí misma, porque la ausencia de comunicación, lo han dicho ya todos los estudiosos del tema, es siempre una comunicación negativa. La empresa concienciada no cuestiona la necesidad del comunicar porque, sencillamente, sabe que no hay otra alternativa 
En el caso concreto de las cooperativas, participan en los mismos mercados que el resto de empresas, tienen que ofrecer productos y servicios y, en consecuencia, deben comunicar su existencia, y deben hacerlo de una manera eficaz. El problema es que

hay una opinión unánime que apunta que las empresas de la economía social no comunican, no muestran sus proyectos, tienen una falta de iniciativa comunicativa, no tienen cultura de proyectar imagen y desconocen que esto pueda influir en su negocio. En consecuencia, esto provoca que la comunicación, en muchos casos, no exista, sea endogámica (solamente dentro del propio sector de actividad), no sea transparente y sea reducida

(Herranz de la Casa y Salinas, 2004: 25)

Como se ha afirmado anteriormente, no es sólo que el desarrollo de la estrategia de comunicación sea clave para el desempeño organizacional, sino que además el desarrollo tecnológico ha originado la aparición de nuevos medios de comunicación que, con Internet a la cabeza, se están incorporando en la planificación comunicativa de todo tipo de empresas y las cooperativas no pueden quedarse al margen. Como señalan Herranz de la Casa y Salinas (2004: 33) las empresas de la economía social, y las cooperativas en particular "deben empezar a manejar los términos del mundo empresarial actual y superar el miedo a conceptos que manejan las empresas" por lo que tienen que integrar a las nuevas tecnologías en su comunicación. Internet, apuntan Cristobal, Montegut y Daries (2017), dota a las cooperativas de una poderosa herramienta de participación y gestión organizacional y ayuda en la consecución sus objetivos económicos reforzando, así, su actividad.

Internet ha proporcionado a las organizaciones cooperativas un poderoso instrumento de comunicación. De hecho, autores como Marcuello y Sanz (2008), Bruque, Vargas, Moyano y Hernández (2002), Cristobal, Montegut y Daries (2017) o Campos y Navarro (2017), entre otros, consideran que, para las cooperativas, por sus particulares características de propiedad y control democrático, apoyados en los principios y valores cooperativos, esa integración de las nuevas tecnologías de la comunicación y de la información debería ser clave en la obtención de ventajas y oportunidades. El problema nuevamente es que esta implementación se está llevando de modo pausado (López, Arcas y Alcón, 2014, Campos y Chaves, 2012, Vázquez, 2010) siendo la presencia de las mismas en redes sociales todavía reducida (Fernández, Bernal, Mozas, Medina y Moral, 2016).

En definitiva, si bien es cierto que las cooperativas engloban a realidades empresariales y sociales de distinto tipo y que no están exentas de peculiaridades propias de su estructura, no lo es menos que la importancia de la comunicación para estas organizaciones debería ser equiparable a la de cualquier empresa, configurándose como un elemento fundamental de gestión. Como apuntan Herranz de la Casa y Salinas

no hay que olvidar que las cooperativas son empresas y como tales su funcionamiento depende de la venta de productos y servicios. La comunicación es un instrumento que puede ayudar a esto no sólo en la fase de comercialización sino en todo el proceso. Esta idea es un 
eje central para que la comunicación adquiera una verdadera importancia estratégica en las cooperativas

El problema está en que estas organizaciones tienen como tarea pendiente la asignatura de la comunicación y, en particular, la gestión de su comunicación digital. De hecho, para Salinas (2004) es en el campo de la comunicación donde estas organizaciones tienen grandes carencias y lagunas, concediéndoles poca relevancia a estas cuestiones en sus estrategias organizacionales y gestionando la misma de manera deficiente.

\section{Metodología}

La encuesta online a partir de un cuestionario estructurado ha sido el instrumento metodológico elegido para lograr la consecución de los objetivos ya que permite "obtener, de manera sistemática y ordenada, información de la población investigada sobre las variables o temas que nos interese conocer" (Soler, 2001: 21).

Esta herramienta cuantitativa no sólo es una de las más conocidas, sino que, además, es una de las más completas de las utilizadas por los investigadores en comunicación. Desde el punto de vista científico constituyen, sin duda, un instrumento valioso de conocimiento de la realidad social y política y en ese sentido son ampliamente utilizadas en la investigación en ciencias sociales.

Previo a la elaboración del cuestionario, se han definido las siguientes variables de estudio, fundamentadas en los trabajos de Túñez, Costa y Míguez (2018); Román (2016); Adigital (2014) y Paniagua y Gómez (2012).

Estas variables que se van medir son:

1. Importancia de la comunicación

2. Nivel de inversión

3. Planificación comunicativa

4. Asunción de tareas

5. Definición de objetivos

6. Estrategias

7. Presencia en RRSS

8. Seguidores en RRSS

9. Implementación de acciones.

De cara a la determinación de la población objeto de estudio y ante la necesidad de contar con un registro de cooperativas de suficiente prestigio y entidad, se recurrió al informe "Las empresas más relevantes de la economía social 2019-2020" que desde 2007 elabora la Confederación Empresarial Española de la Economía Social (CEPES) y que incluye un ranking de cooperativas ordenados por nivel de facturación y que integra en total a 702 entidades 
cooperativas que se configuran como el universo de estudio. El cuestionario definitivo se implementó a través de la herramienta Google Forms y ha estado habilitado desde el 30 de abril y hasta el 27 de mayo. La muestra final, conformada por 338 cooperativas de toda España, se ha seleccionado a través de un muestreo no probabilístico por conveniencia. Las encuestas han sido respondidas de manera anónima y los resultados han sido analizados con el software estadístico SPSS.

En cuanto a la tipología final de cooperativas que han respondido al cuestionario, si se analiza la trayectoria se trata en su mayoría de empresas "maduras" consolidadas en el mercado y que llevan funcionando más de 10 años.

\section{Gráfico 1. Trayectoria de la cooperativa}

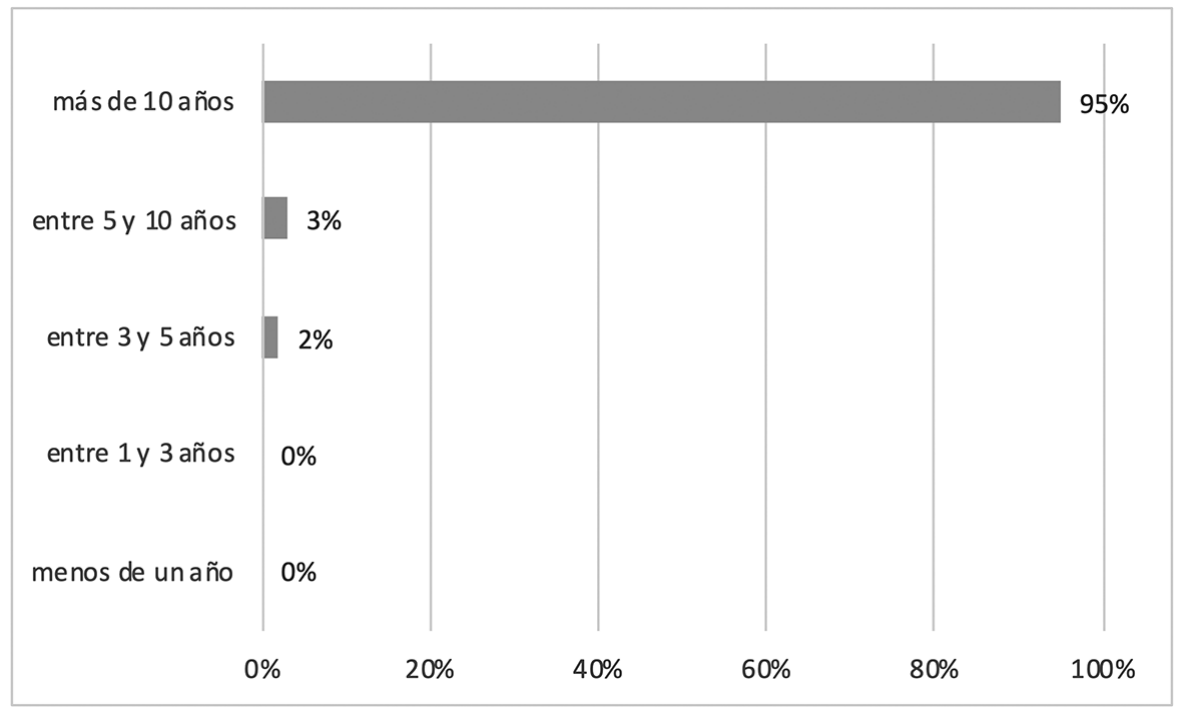

Fuente: Elaboración propia.

En relación al tipo de cooperativa, son las agrarias (63,3\%) el tipo predominante en la muestra, seguida de las cooperativas de trabajo asociado $(15,1 \%)$ y las de servicios $(7,7 \%)$ y ya, en menor medida, las de consumidores y usuarios $(5,3 \%)$, de iniciativa social $(4,4 \%)$ o de enseñanza $(2,7 \%)$. 


\section{Gráfico 2. Tipo de cooperativa}

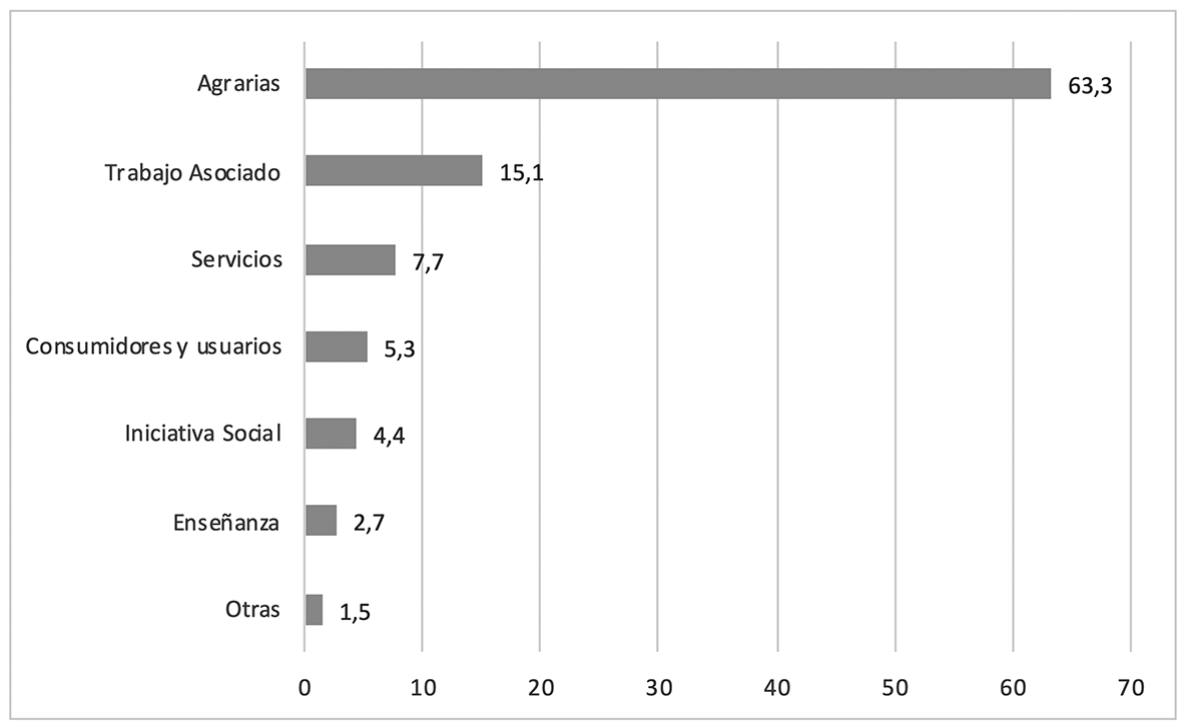

Fuente: Elaboración propia.

En función al número de empleados, en la muestra predominan las pequeñas y medianas empresas (de 10 a 249 empleados -51,7\% de la muestra-). Por su parte, las empresas unipersonales y las microempresas, que caracterizan el tejido empresarial español, sólo suponen el $21,6 \%$ de la muestra, mientras que las cooperativas que se consideran grandes empresas (250 empleados o más) suponen el $26,7 \%$. 


\section{Gráfico 3. Tamaño de las cooperativas}

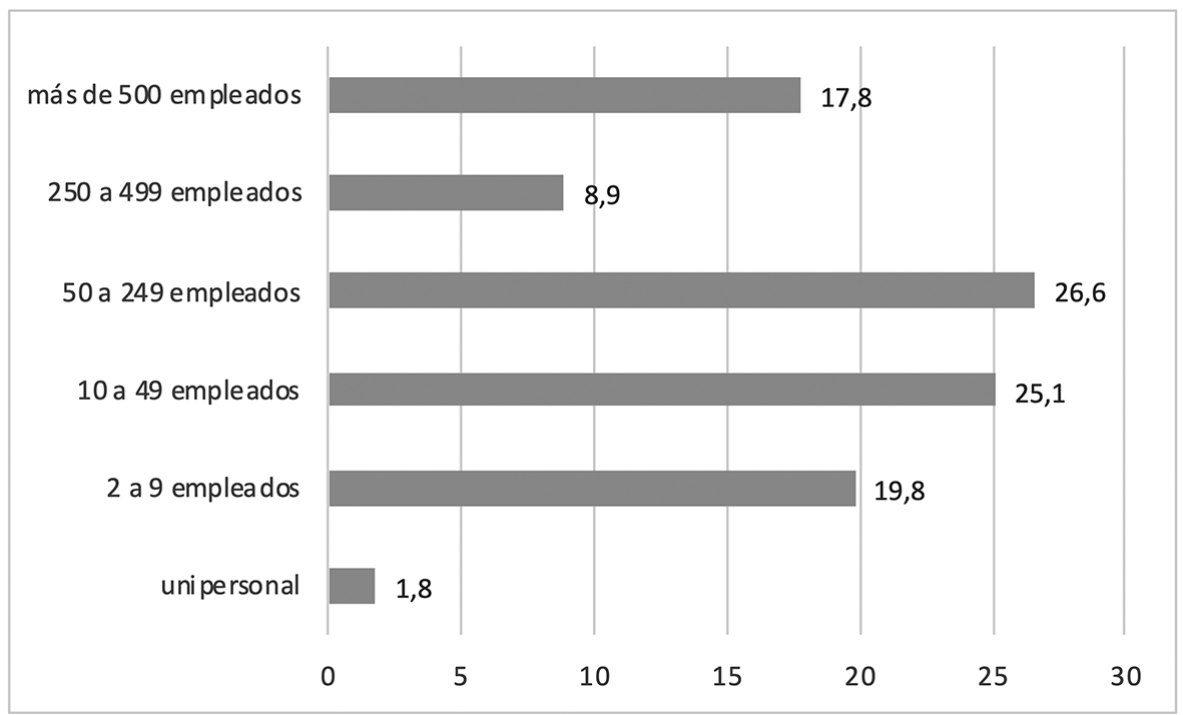

Fuente: Elaboración propia.

En cuanto al ámbito territorial en el que desarrollan su actividad, el 50\% de la muestra lo hace a nivel internacional, mientras que un 23,1\% la realiza en el ámbito nacional o autonómico (16,5\%). Tan sólo el 10,7\% desarrolla su actividad exclusivamente a nivel local. 


\section{Gráfico 4. Ámbito territorial en el que desarrollan su actividad}

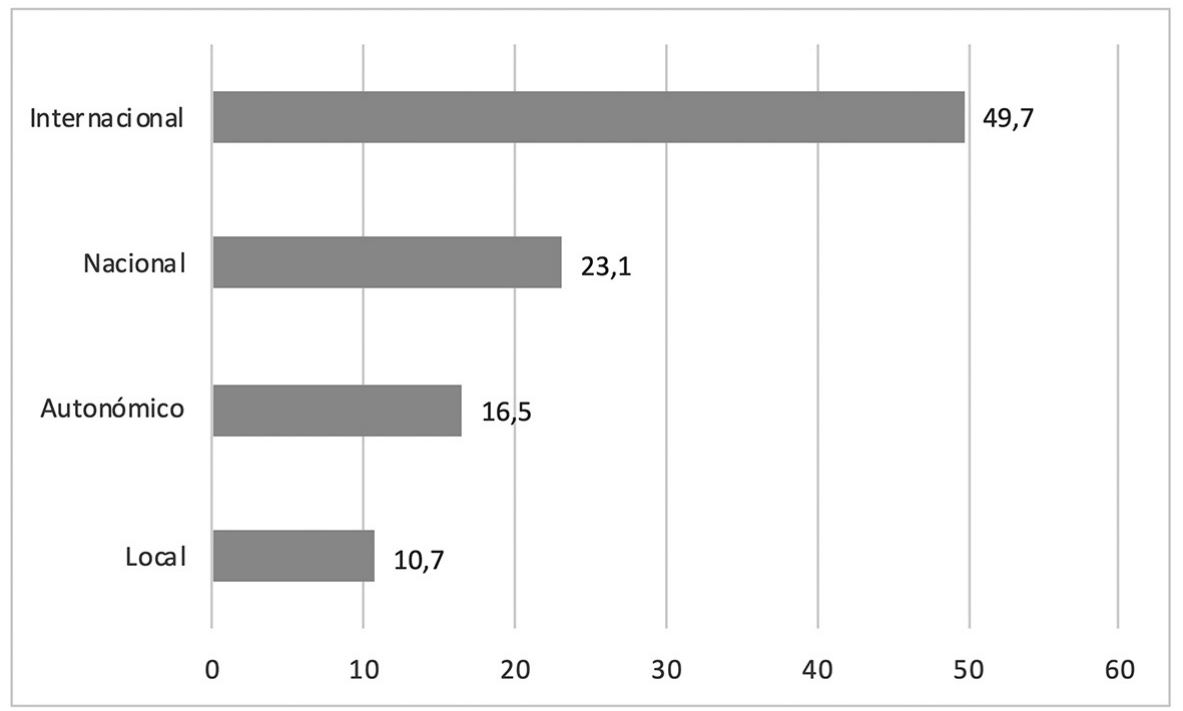

Fuente: Elaboración propia.

\section{Resultados}

El primer aspecto sobre el que se les ha cuestionado a las cooperativas, a través de una escala Likert 1-5 (siendo 1 nada importante y 5 fundamental) es la importancia que le conceden a la comunicación, desde una perspectiva general, dentro de la gestión empresarial. Estas empresas le dan mucha importancia a la comunicación en su estrategia empresarial y la consideran como fundamental o muy importante (87,6\%). La media, se sitúa en el 4,3, para una desviación de ,730. De hecho, ninguna la considera como nada importante y tan sólo el 1,8\% considera que dicha comunicación es algo importante. 


\section{Gráfico 5. Importancia de la comunicación para las cooperativas}

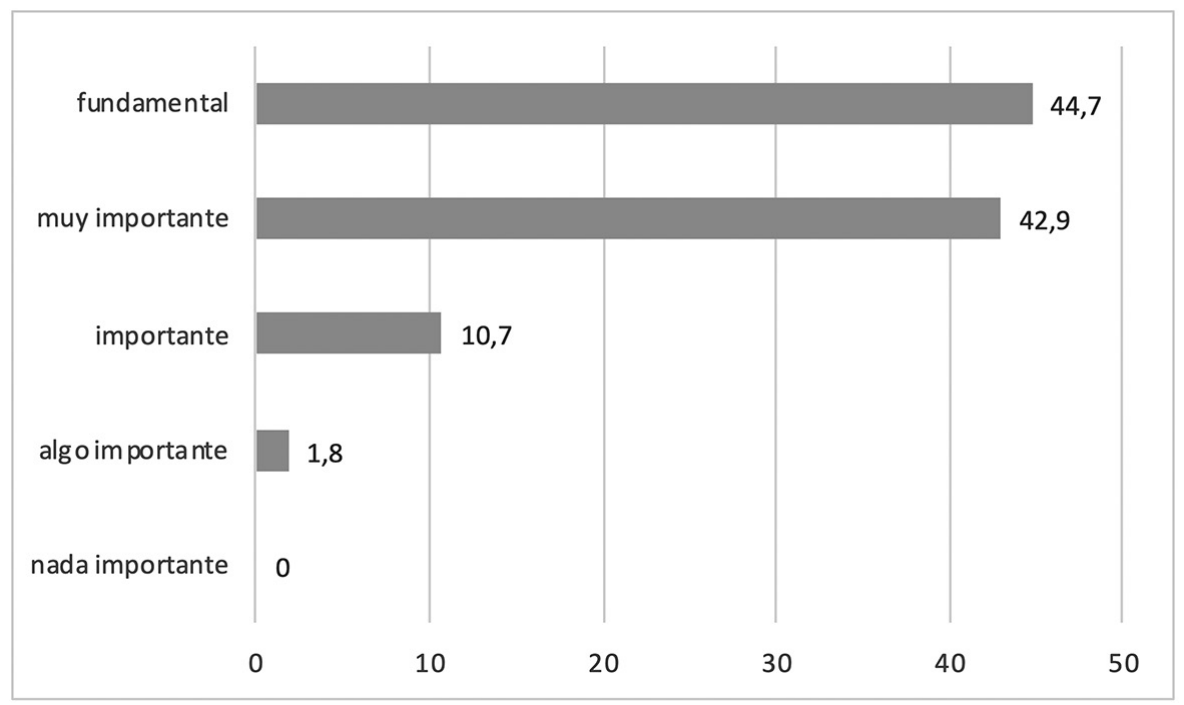

Fuente: Elaboración propia.

Cuestión distinta es cuando se pregunta por un dato más tangible como la inversión que hacen en comunicación. Los datos que se desprenden de las respuestas a la pregunta sobre la inversión en comunicación no pueden entenderse de manera positiva. El porcentaje de organizaciones que invierten menos del 5\% de su presupuesto en el desarrollo de la comunicación es del 81,9\%, por tan sólo un 18,1\% que invierte entre el 5\% y el 20\%. También es de destacar que ninguna cooperativa invierte más del $20 \%$ en comunicación. 


\section{Gráfico 6. Inversión en comunicación}

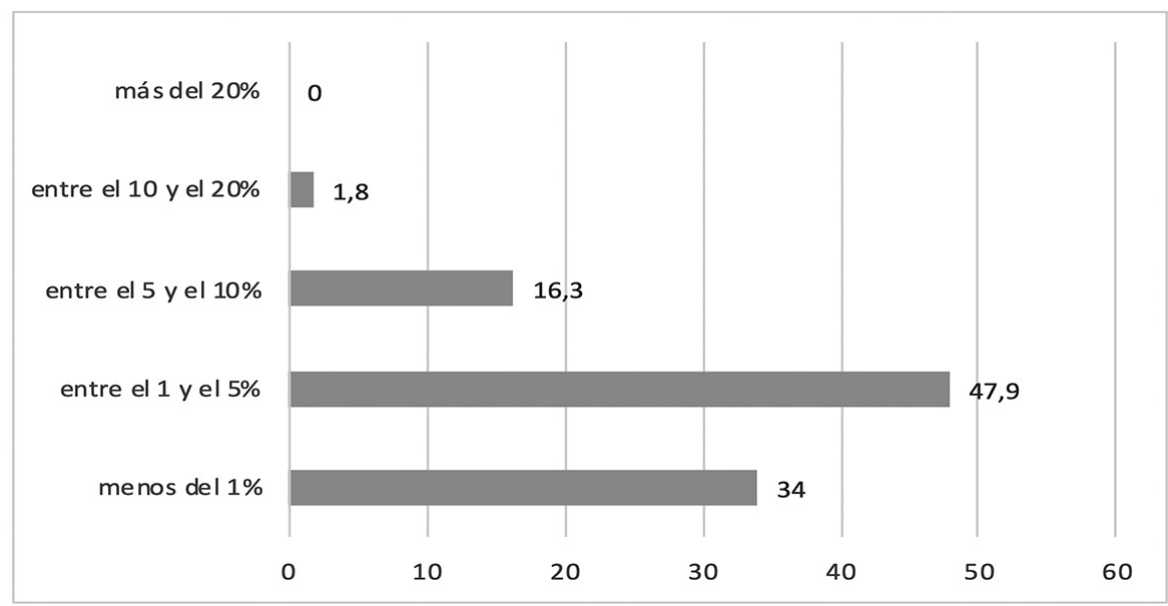

Fuente: Elaboración propia.

Por otro lado, y centrados ya en la comunicación online, se ha querido conocer cuánto se destina, de dicha inversión global, a la parte digital. Es mayoritario el número de cooperativas (53\%) que invierte menos del 5\% en comunicación online. En el otro lado está el porcentaje que destina o más del $50 \%(8,9 \%)$ o incluso todo el presupuesto $(3,6 \%)$ en desarrollar acciones de comunicación digital. En cualquier caso, y considerando que ya la inversión en comunicación es baja en general, los fondos destinados a esta actividad son aún menores. 


\section{Gráfico 7. Inversión en comunicación digital}

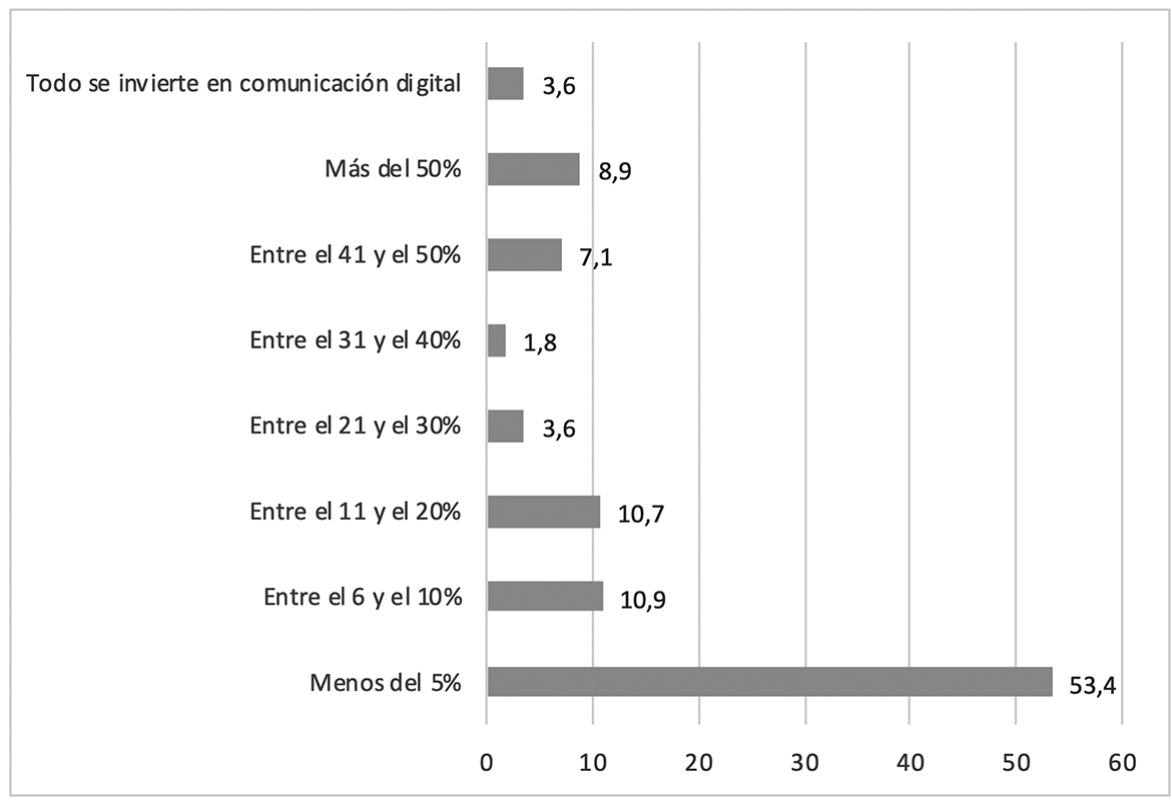

Fuente: Elaboración propia.

El siguiente aspecto que se ha medido es la existencia o no de planes de comunicación o marketing digital que guíen las decisiones y establezcan un marco sobre el que desarrollar las estrategias y acciones comunicativas. En prácticamente el 61\% de los casos no existe planificación, por lo que se puede considerar que las decisiones se toman de forma intuitiva 0 improvisada.

\section{Tabla 1. Planificación de la comunicación}

\begin{tabular}{l|c|c} 
& sí & No \\
\hline Existencia de planes de marketing digital & $39,3 \%$ & $60,7 \%$ \\
\hline
\end{tabular}

Fuente: Elaboración propia.

En cuanto al análisis de la asunción de las tareas de comunicación por parte de las cooperativas los resultados no son malos. Por un lado, en tan sólo el 5\% nadie asume las tareas de comunicación, lo que significa que en el 95\% restante al menos hay una persona responsable de gestionar la comunicación y, por tanto, las cooperativas son conscientes de que hay que de- 
dicar recursos humanos a esta tarea. De hecho, en el 60,6\% de los casos el desempeño de estas funciones se realiza en exclusiva, ya sea por un departamento específico de marketing digital independiente del departamento de comunicación general (8,9\%), el mismo departamento de comunicación que gestiona la comunicación global $(35,5 \%)$ o se externaliza con especialistas (16\%).

En contraposición, si se profundiza en ese dato, en el 18\% de las cooperativas, la persona que se ocupa de la comunicación digital desempeña más funciones dentro de la empresa o se trata de un departamento de informática/técnico (14\%) o es la misma dirección (2\%), lo que implica que esa persona o personas no se están dedicando únicamente a gestionar la comunicación de la cooperativa y, además, tampoco tiene por que tener formación específica.

\section{Gráfico 8. ¿Quién gestiona la comunicación digital?}

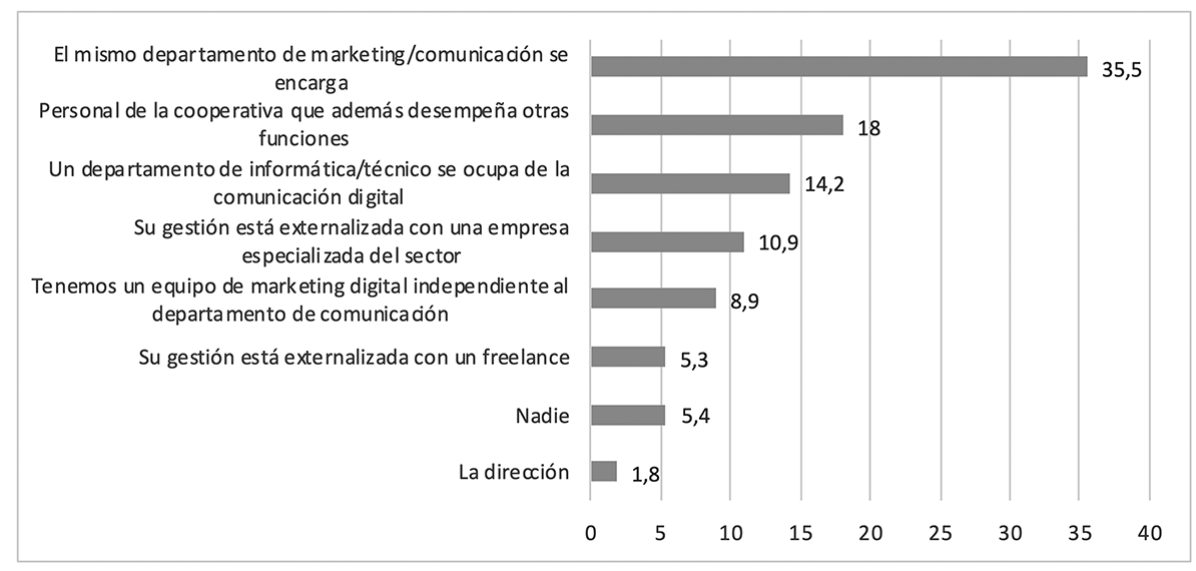

Fuente: Elaboración propia.

En lo referente a los objetivos de comunicación a alcanzar con la estrategia digital, los más destacados son de tipo corporativo y no estrictamente comercial. Concretamente mejorar la imagen de la empresa $(83,6 \%)$ e incrementar la notoriedad de marca $(80 \%)$, lo que muestra la preocupación de las cooperativas por tener una posición favorable en la mente de sus públicos incluso por encima de vender sus productos o servicios. Si bien no es menos cierto que también persiguen este tipo de objetivos. Vender o promocionar productos/servicios $(74,5 \%)$ y fidelizar clientes $(70,9 \%)$ ocupan el tercer y cuarto lugar en esta relación. En contra, es destacable que dos cuestiones tan importantes como la comunicación de crisis (32,7\%) o vigilar lo que hace la competencia $(36,3 \%)$ son tenidos menos en cuenta, a pesar de la importancia que estas cuestiones tienen para la marcha de una organización. Por otro lado, y dada la relevancia que para estas organizaciones tiene la comunicación con sus socios y cooperativistas, el porcentaje de cooperativas que incluyen objetivos de comunicación interna es mejorable: tan sólo el 49\% los incluye en sus planes comunicativos. 


\section{Tabla 2. Objetivos de la comunicación digital}

\begin{tabular}{l|c}
\hline Mejorar la imagen de la empresa & $\%$ \\
\hline Incrementar la notoriedad de marca & $83,6 \%$ \\
\hline Vender o promocionar productos/servicios & $80,0 \%$ \\
\hline Fidelizar clientes & $74,5 \%$ \\
\hline Recoger opiniones de los clientes & $70,9 \%$ \\
\hline Generar contactos (leads) & $63,6 \%$ \\
\hline Mejorar el tráfico a la web & $58,2 \%$ \\
\hline Mejorar el SEO & $52,8 \%$ \\
\hline Comunicación interna & $50,1 \%$ \\
\hline Observar a la competencia & $49,0 \%$ \\
\hline Comunicación de crisis & $36,3 \%$ \\
\hline
\end{tabular}

Fuente: Elaboración propia.

En cuanto a las principales estrategias abordadas por las cooperativas a la hora de desarrollar sus planes de comunicación digital, la estrategia web (92,6\%) es la principal. Otras como la publicidad en Internet $(44,7 \%)$ o la estrategia de social media marketing $(40,8 \%)$ son desarrolladas en menor medida. Las cooperativas le conceden una gran importancia al hecho de contar con una página web como principal portal comunicativo/informativo, pero, en cambio, las estrategias que fomentan la comunicación directa con los públicos y la interactividad, como las basadas en los social media o en el email marketing, presentan menos interés.

\section{Tabla 3. Estrategia digital}

\begin{tabular}{l|c}
\hline \multicolumn{2}{c}{$\%$} \\
\hline Estrategia web & $92,6 \%$ \\
\hline Estrategia publicitaria & $44,7 \%$ \\
\hline Estrategia de Social Media Marketing & $40,8 \%$ \\
\hline Estrategia de email marketing & $37,9 \%$ \\
\hline
\end{tabular}

Fuente: Elaboración propia. 
Toda vez que se comprueba la importancia de la web para las cooperativas, también es interesante analizar más en profundidad la estrategia de social media marketing, a través del estudio de las principales RRSS en las que están activos. Del estudio de la presencia y número de seguidores en las principales redes sociales se comprueba como Facebook es la red social más utilizada por las empresas, con un nivel de adopción superior al 80\%. Las otras dos RRSS más generalistas, Twitter e Instagram, muestran un porcentaje de presencia de las cooperativas similar, aunque no tan alto como Facebook. En el caso de Instagram (50\%), esta cifra sorprende dado el alto crecimiento que esta red ha experimentado en los últimos tiempos y que la ha posicionado como una de las más importantes a la hora de desarrollar la comunicación digital por parte de las empresas.

Tabla 4. Presencia en redes sociales y número de seguidores

\begin{tabular}{|c|c|c|c|c|c|c|c|}
\hline & Facebook & Twitter & Instagram & Linkedin & Youtube & Pinterest & Tictoc \\
\hline $\begin{array}{l}\text { no tenemos perfil } \\
\text { en esta red social }\end{array}$ & 17,7 & 48 & 50 & 44,6 & 49,7 & 92,8 & 96,4 \\
\hline menos de 100 & 7,1 & 1,7 & 3,4 & 8,9 & 14,5 & 1,8 & 0 \\
\hline entre 101 y 500 & 14,2 & 12,7 & 10,7 & 12,7 & 19,8 & 0 & 0 \\
\hline entre 501 y 1000 & 9,2 & 14,5 & 7,4 & 12,4 & 7,1 & 0 & 0 \\
\hline entre 1001 y 5000 & 25,1 & 0 & 23,1 & 0 & 5,3 & 1,8 & 0 \\
\hline $\begin{array}{l}\text { entre } 5001 \text { y } \\
10000\end{array}$ & 12,4 & 7,1 & & 1,8 & 0 & 0 & 0 \\
\hline $\begin{array}{l}\text { entre } 10001 \text { y } \\
50000\end{array}$ & 10,7 & 12,4 & 1,8 & 16 & 0 & 0 & 0 \\
\hline más de 50000 & 3,6 & 3,6 & 3,6 & 3,6 & 3,6 & 3,6 & 3,6 \\
\hline
\end{tabular}

Fuente: Elaboración Propia.

Finalmente, se ha medido el tipo de uso que hacen de las RRSS a partir de las actividades que realizan en cada una de ellas. Destaca el bajo porcentaje de cooperativas que miden el retorno económico de la inversión realizada en medios digitales $(30,9 \%)$ y que está incluso por debajo del índice de empresas que sí miden otro tipo de indicadores de contenido no económico (43,6\%). Por otro lado, el porcentaje de empresas que usa las redes sociales para acciones publicitarias no pagadas u orgánicas es cercano al 60\% es bueno, si bien este tipo de acción no es tan efectiva como contratar publicidad pagada, y es aquí donde las cooperativas muestran mayores carencias. 
Tabla 5. Gestión de las redes sociales

\begin{tabular}{|c|c|}
\hline & $\%$ \\
\hline Se utiliza para campañas/acciones publicitarias orgánicas & $56,3 \%$ \\
\hline Se monitoriza/analiza lo que se dice sobre la empresa/marca & $49,0 \%$ \\
\hline Se miden indicadores o KPIS no económicos & $43,6 \%$ \\
\hline Se contrata publicidad pagada & $38,1 \%$ \\
\hline Se mide el retorno económico de la inversión & $30,9 \%$ \\
\hline
\end{tabular}

Fuente: Elaboración propia.

\subsection{Análisis multivariante}

Con la idea de profundizar en el grado de importancia que las cooperativas conceden a la comunicación, se ha investigado pormenorizadamente como afectan la trayectoria temporal, el tipo de cooperativa, el tamaño y el ámbito territorial a dicha gestión.

Para ello, y debido a la falta de normalidad con la que se distribuye la variable grado de importancia que las cooperativas conceden a la comunicación $(\mathrm{Z}=0,276 ; \mathrm{p}=0,000)$ y al tamaño de algunos grupos de las variables de clasificación (menos de 30 casos) se han aplicado sendos test no paramétricos de Kruskal-Wallis para llevar a cabo los análisis.

Los resultados muestran que no existen diferencias significativas al valorar la importancia que las cooperativas conceden a la comunicación según la trayectoria temporal en años $(\chi 2=1,364 ; p=0.506)$, ni tampoco al estudiar el tipo de cooperativa $(\chi 2=15.331 ; p=0.053)$.

Sin embargo, al considerar el tamaño (en número de empleados) hallamos diferencias significativas entre los grupos objeto de estudio $(\chi 2=40,560 ; p=0.000)$. Específicamente descubrimos que las empresas de 250 a 499 empleados son las que más valoran la importancia que tiene la comunicación $(\bar{x}=4,73)$. En el lado opuesto, encontramos las cooperativas unipersonales que valoran en menor medida la importancia de la comunicación $(\bar{x}=3,67)$ (ver gráfico 9).

Profundizando en la importancia que las cooperativas conceden a la comunicación de acuerdo con el ámbito territorial donde desarrollan su actividad, también descubrimos diferencias significativas entre los distintos ámbitos territoriales $(\chi 2=21,872 ; \mathrm{p}=0.000)$. Particularmente detectamos que las empresas de ámbito nacional y local, son las que más valoran la importancia que tiene la comunicación $(\bar{x}=4,41)$. Mientras que las de ámbito autonómico son las que menos importancia otorgan a sus comunicaciones $(\bar{x}=3,91)$ (ver gráfico 10$)$. 


\section{Gráfico 9. Importancia de la comunicación según el número de empleados}

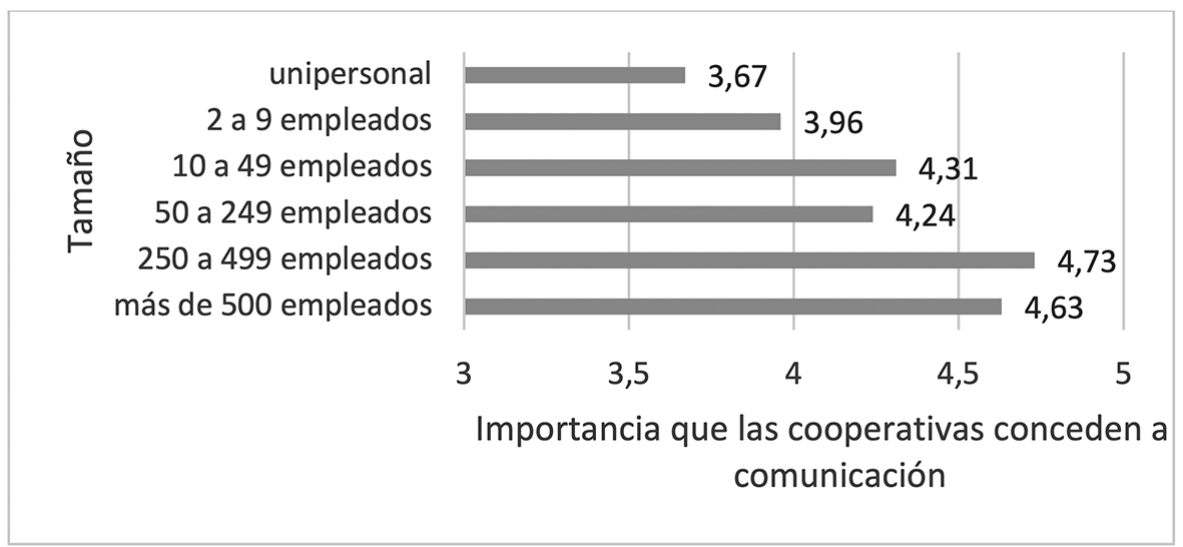

Fuente: Elaboración propia.

\section{Gráfico 10. Importancia de la comunicación según el ámbito de actuación}

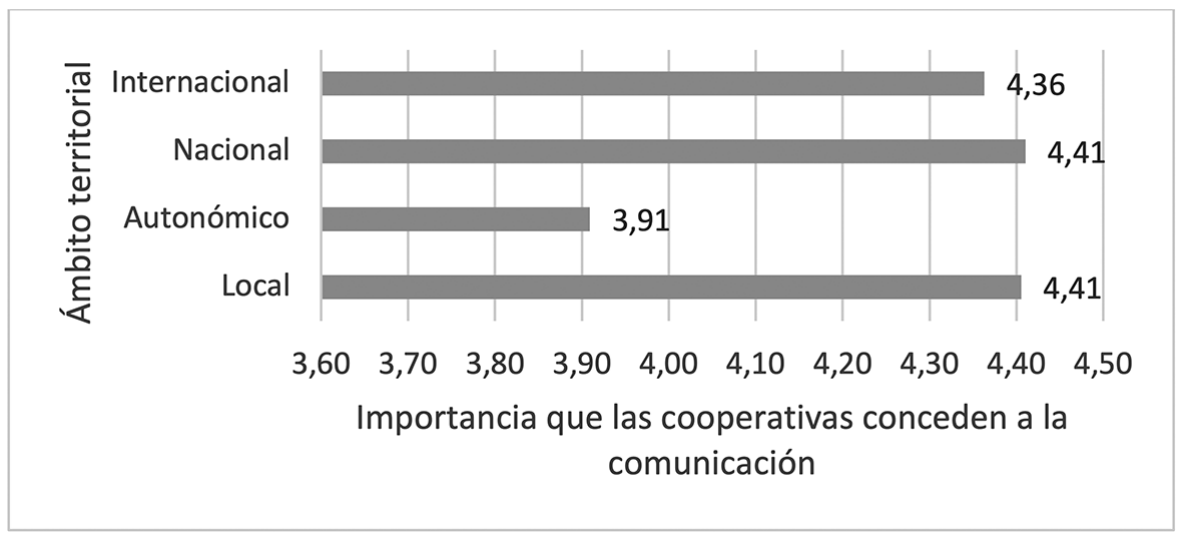

Fuente: Elaboración propia.

En esta relación entre la importancia que las cooperativas con el resto de variables del estudio, también se han encontrado diferencias significativas con el porcentaje de inversión destinado a comunicación $(\chi 2=61,534 ; p=0.000)$, con el responsable de gestionar la comunicación $(\chi 2=39,698 ; p=0.000)$, con la planificación de la estrategia digital $(Z=-5,985 ; p=0,000)$. También se encuentran diferencias según los objetivos de comunicación se basen en vender productos o servicios $(Z=-3,892 ; p=0,000)$, fidelizar clientes $(Z=-4,843 ; p=0,000)$, incremen- 
tar la notoriedad de marca $(\mathrm{Z}=-6,277 ; \mathrm{p}=0,000)$, aumentar los nuevos clientes $(\mathrm{Z}=-4,872$; $\mathrm{p}=0,000)$, promocionar productos/servicios $(\mathrm{Z}=-3,632 ; \mathrm{p}=0,000)$ y la comunicación interna $(\mathrm{Z}=-2,451 ; \mathrm{p}=0,000)$. Por último, se ha estudiado la existencia de diferencias al valorar la importancia de la comunicación considerando el número de seguidores que tienen las cooperativas en redes sociales y los resultados muestran diferencias según el número de seguidores que tienen en Facebook $(\chi 2=73,754 ; p=0,000)$, Twitter $(\chi 2=24,660 ; p=0,000)$, Instagram $(\chi 2=50,591 ; p=0,000)$, Linkedin $(\chi 2=62,599 ; p=0,000)$, Youtube $(2=39,493 ; p=0,000)$, y Pinterest $(\chi 2=36,009 ; p=0,000)$.

Finalmente, se aplicó una prueba chi-cuadrado que sirvió para conocer la existencia de correlación entre las variables cualitativas objeto de estudio. Los resultados indican que existe una asociación positiva media entre las variables estudiadas salvo entre los años de funcionamiento y el ámbito territorial que presenta una correlación débil. Además, no encontramos correlación entre los años de funcionamiento y el número de empleados (ver tabla 6).

\section{Tabla 6. Coeficiente de contingencia entre variables cualitativas}

\begin{tabular}{|c|c|c|c|}
\hline Variables & $\chi^{2}$ & p-valor & $\begin{array}{c}\text { Coeficiente de } \\
\text { contingencia }\end{array}$ \\
\hline Años de funcionamiento*tipo de cooperativa & 125,999 & $0,000^{\text {k文 }}$ & 0,521 \\
\hline Años de funcionamiento*ámbito territorial & 20,517 & $0,002^{k<k}$ & 0,239 \\
\hline Años de funcionamiento*número de empleados & 22,280 & 0,14 & 0,249 \\
\hline Tipo de cooperativa*ámbito territorial & 102,206 & $0,000^{\text {*kंस }}$ & 0,482 \\
\hline Tipo de cooperativa*número de empleados & 107,500 & $0,000^{* * 2 \times}$ & 0,491 \\
\hline Ámbito territorial"número de empleados & 102,429 & $0,000^{* * *}$ & 0,482 \\
\hline
\end{tabular}

** estadístico significativo, indica correlación entre variables.

Fuente: Elaboración propia.

\section{Conclusiones}

Los cambios sociales, la apertura de los mercados, la globalización, la extrema competitividad o la actual crisis derivada del estado de alarma decretado por el gobierno español han colocado a muchas organizaciones entre las que, como no puede ser de otra manera, se encuentran las cooperativas, en una situación de gran incertidumbre. Si para cualquier compañía la comunicación con sus públicos debe ser importante, en la actualidad y en los meses que están por venir, esta actividad debe cobrar una relevancia determinante para su supervivencia. 
En este sentido, las Nuevas Tecnologías de la Información y la Comunicación (NTICS), como Internet, con la Web como máximo exponente, han transformado las formas de comunicación entre las empresas y sus públicos, proporcionando beneficios y ofreciendo nuevos modos, nuevos caminos y nuevas e innovadoras formas de interacción e intercambio de mensajes (Milojevic, Kleut y Ninkovic, 2013) para todos los sujetos implicados en el proceso comunicativo. El efecto que Internet ha causado en el mundo de la comunicación empresarial está fuera de toda duda y ha cambiado las estrategias comunicativas de muchas de ellas. Y otras, que antes no contaban con esta herramienta, empiezan a preocuparse por las mismas. Como apunta Castelló (2010) Internet se configura como el medio idóneo para personalizar el mensaje y facilitar la interacción entre las empresas y sus públicos, transformado la manera en que las empresas se comunican con sus públicos, favoreciendo las relaciones entre éstos y aportando notables beneficios para las organizaciones. La necesidad de diferenciar las organizaciones hace necesaria una estrategia de comunicación online que ponga de manifiesto los esfuerzos de las compañías por integrar a sus públicos en la misma.

Esta investigación ha medido la gestión que de la comunicación digital hacen 338 cooperativas españolas con el fin de determinar cómo la desarrollan, considerando que aquellas que implementen una adecuada gestión comunicativa online, tendrán cierta ventaja y partirán de una mejor posición a la hora de pelear en el mercado. Y, para ello, se han medido una serie de variables clave tales como la importancia dada a la comunicación, el porcentaje de inversión destinado a la comunicación digital, la existencia de planes estratégicos en el entorno online, los tipos de objetivos que se persiguen y el tipo de estrategia que se implementa, quién asume las tareas digitales y, más específicamente, que presencia tienen en RRSS y que acciones desarrollan en las mismas.

De los resultados del estudio se desprende que, si bien para las cooperativas la comunicación es una herramienta clave, esto no se ve reflejado ni en la inversión destinada a esta estrategia ni en la existencia de planes de marketing digital. Las cooperativas destinan pocos recursos económicos a la comunicación online si bien, según el porcentaje de inversión cuanto mayor es este porcentaje de inversión en comunicación, mayor es la importancia que otorgan las cooperativas a la comunicación.

Además, su gestión desde una perspectiva planificada y estratégica es insuficiente, lo que está en línea con trabajos como los de Herranz de la Casa y Salinas (2004) que hablan de la necesidad de mayor planificación en comunicación en las cooperativas. En este sentido, son las cooperativas que consideran muy relevante esta actividad, aquellas que más cuentan con este tipo de planes.

Por otro lado, se pone de manifiesto que al contrario de lo que se podía pensar, no son las cooperativas con un mayor número de empleados o aquellas que operan en el mercado internacional las que más importancia brindan a la comunicación. Aunque la tendencia en las cooperativas es aumentar la importancia de la comunicación a medida que van creciendo en número de empleados, parece que este patrón se frena en aquellas que tienen entre 50 y 249 trabajadores y en las que tienen más de 500 empleados. Según el ámbito de actuación no se aprecia un patrón que indique una mayor importancia hacia la comunicación a medida que 
aumentan los mercados de actividad, aunque son las empresas con mercado nacional y local las que más valoran la comunicación.

Desde un punto de vista positivo hay que entender que los objetivos comunicativos se plantean en términos corporativos más que comerciales y mejorar la imagen, alcanzar notoriedad, fidelizar clientes destacan entre los fines de estas empresas, por encima de otros más marketinianos como promocionar y vender productos y servicios. En este sentido, una carencia tiene que ver con la comunicación interna. Estas organizaciones por su carácter eminentemente social y democrático, en las que los cooperativistas son una pieza clave, no plantean sus objetivos comunicacionales en términos de comunicación interna. Como apunta Herranz de la Casa (2004: 24) “ ¿qué futuro le espera a una empresa que se autogestiona si no funciona un adecuado flujo de comunicación?"

Otra de las variables que se ha medido tiene que ver con el desarrollo de las estrategias digitales de comunicación y, aquí, las cooperativas optan por potenciar la web como portal de información por delante de estrategias más interactivas y en línea con la web 2.0, especialmente la de social media. En este sentido, destaca la presencia de las cooperativas en las redes sociales más generalistas, especialmente Facebook si bien, se debería potenciar la presencia de estar organizaciones, dada su relevancia actual entre la población, en redes sociales como Instagram o Youtube.

Finalmente, tampoco las cooperativas estudiadas desarrollan acciones clave en la gestión de la comunicación digital como medir el retorno de la inversión o estudiar KPIs no económicos y que son fundamentales a la hora de analizar las estrategias que se están desarrollando.

Es por todo esto que se puede afirmar que las cooperativas analizadas se sitúan en un nivel medio-bajo en cuanto a la gestión que de la comunicación digital hacen. Falta de inversión y planificación, preferencia por la web frente al social media o a la publicidad pagada y ausencia de medición permiten afirmar que las cooperativas deben potenciar mucho más su comunicación digital e impulsar la misma a través de la inversión y el desarrollo de planes estratégicos.

A la vista de estos resultados las cosas no han cambiado mucho a pesar del avance tecnológico y las oportunidades que la comunicación digital ofrece a las organizaciones y es que, ya en 2004, Herranz de la Casa y Salinas afirmaban que "hay una opinión unánime que apunta que las empresas de la economía social no comunican, no muestran sus proyectos, tienen una falta de iniciativa comunicativa, no tienen cultura de proyectar imagen y desconocen que esto pueda influir en su negocio. En consecuencia, esto provoca que la comunicación, en muchos casos, no exista" (p. 25). Hoy día, las cooperativas siguen sin tener una visión estratégica de su comunicación (digital), siendo escasos los recursos que dedican a la misma tanto en términos de planificación como de inversión, lo que tiene como consecuencia una escasa visibilidad de estas organizaciones dentro de la sociedad que ayude al desarrollo y crecimiento de las mismas. 


\section{Bibliografía}

ADIGITAL (2014): Informe sobre usos de redes sociales en empresas 2014.

ALMANSA, A. (2011): Del gabinete de prensa al gabinete de comunicación. La dirección de comunicación en la actualidad, Comunicación Social, ediciones y publicaciones, Madrid.

BAYÓN, M., DEL CASTILLO, J. \& ARTETA, R. (1992): La empresa ante los medios de comunicación, Ediciones Deusto, Bilbao.

BORT, I., GARCÍA, S. \& MARTÍN, M. (2011): Nuevas tendencias e hibridaciones de los discursos audiovisuales en la cultura digital contemporánea, Ediciones de las Ciencias Sociales, Madrid.

BRUQUE, S., VARGAS, A., MOYANO, J. \& HERNÁNDEZ, M.J. (2002): “Estructura de la propiedad, tecnologías de la información y ventaja competitiva. Una aproximación empírica", Revista de Economía y Empresa, 44, 105-125.

CABRA DE LUNA, M.A. (2003): "Economía social e instituciones europeas". En: VV.AA., La economía social y el tercer sector, Escuela Libre Editorial, Madrid, 169-234.

CAMPOS, V. \& CHAVES, R. (2012): "El papel de las cooperativas en la crisis agraria. Estudio empírico aplicado a la agricultura mediterránea española", Cuadernos de Desarrollo Rural, 9(69), 175-194.

CAMPOS, V. \& NAVARRO, C. (2017): "Participación en redes organizacionales y uso de las tecnologías de la información y la comunicación, un estudio de su impacto en los resultados de las cooperativas de enseñanza de la comunidad valenciana", REVESCO. Revista de Estudios Cooperativos, 124, 32-46. DOI: 10.5209/REVE.56130.

CANALS, J. (2001): "La estrategia de la empresa en la era de Internet", Información Comercial Española, 793.

CAPRIOTTI, P. \& ZELER, I. (2020): “Comparing Facebook as an interactive communication tool for companies in LatAm and worldwide", Communication \& Society, 33 (3), 119-136.

DOI: https://doi.org/10.15581/003.33.3.119-136.

CARRERAS, R. (2011): ¿Cómo construir una sala de prensa 2.0? Disponible en http://www.territoriocreativo.es.

CASTELLÓ, A. (2010). "La orientación empresarial hacia el cliente en la Web 2.0”, Miguel Hernández Communication Journal, 1, 99-131. D0I:10.21134/MHCJ.V1I1.19. 
CASTELLÓ, A. \& MONTSERRAT, J. (2012): “La comunicación digital de la empresa de franquicia: uso y presencia en los medios sociales", adComunica. Revista de Estrategias, tendencias e innovación en comunicación, 3, 105-124, D0I: http://dx.doi.org/10.6035/2174-0992.2012.3.7.

CASTELLÓ MARTÍNEZ, A., DEL PINO ROMERO C. \& RAMOS, I (2014): “Twitter como canal de comunicación corporativa y publicitaria", Communication \& Society, 27 (2), 21-54.

CHAVES, R., MONZÓN, J.L. \& ZARAGOZA, G. (2013): "La economía social: concepto, macromagnitudes y yacimiento de empleo para el trabajo social", Cuadernos de Trabajo Social, 26 (1), 19-29. DOI: https://doi.org/10.5209/rev_CUTS.2013.v26.n1.40269.

CHUNG, A. Q. H., ANDREEV, P., BENYOUCEF, M., DUANE, A. \& O'REILLY, P. (2017): “Managing an organisation's social media presence: An empirical stages of growth model”, International Journal of Information Management, 37 (1), 1405-1417.

D0I: https://www.doi.org/10.1016/j.ijinfomgt.2016.10.003.

CONFEDERACIÓN EMPRESARIAL ESPAÑOLA DE LA ECONOMÍA SOCIAL (CEPES) (2020): Las empresas más relevantes de la economía social 2019-2020. Disponible en: https:// www.cepes.es/noticias/620_informe-cepes-las-empresas-mas-relevantes-economia-social-2019-2020-muestra-fortaleza-liderazgo-este.

CONGOSTO, Ma - (2015): "Elecciones Europeas 2014: Viralidad de los mensajes en Twitter", REDES-Revista hispana para el análisis de redes sociales, 26 (1), 23-52.

DOI: http://dx.doi.org/10.5565/rev/redes.529.

COTARELO, R. (2013): Ciberpolítica. Las nuevas formas de acción y comunicación políticas”, Tirant lo Blanch, Valencia.

CRIADO, J.I., MARTÍNEZ, G. \& SILVAN, A. (2012): "Twitter en campaña: las elecciones municipales españolas de 2011", RIPS, 12 (1), 93-113.

CRISTOBAL, E., MONTEGUT, Y. \& DARIES, N. (2017): "Cooperativismo 2.0: presencia en Internet y desarrollo del comercio electrónico en las cooperativas oleícolas de Cataluña", REVESCO. Revista de Estudios Cooperativos, 124, 47-73. D0I: 10.5209/REVE.54926.

DE CHERNATONY, L. (2001): "Succeeding with brands on the Internet", Journal of Brand Management, 8(3), 186-95. D0I: https://doi.org/10.1057/palgrave.bm.2540019.

FERNÁNDEZ, D., BERNAL, E., MOZAS, A., MEDINA, M.J. \& MORAL, E. (2015): “El sector cooperativo oleícola y el uso de las TIC: un estudio comparativo respecto a otras formas Jurídicas". REVESCO. Revista de Estudios Cooperativos, 120, 53-75.

DOI: 10.5209/rev_REVE.2016.v120.49700. 
GARCÍA, M. (2012): La comunicación de la marca en las pymes a través de sus sedes webs. el caso de las pymes extremeñas. El caso de las PYMES extremeñas, tesis doctoral, Universidad de Extremadura.

GARCÍA, M. \& CASTILLO, A. (2010): "Webs usables y accesibles en PYMES. Retos para el futuro", Revista Latina de Comunicación Social, 65, 392-409.

DOI: 10.4185/RLCS-65-2010-908-392-409.

HERRANZ DE LA CASA, J.M. \& SALINAS, F. (2004): La comunicación en el ámbito de la economía social, Servicio de Publicaciones Universidad de Ávila, Ávila.

JIVKOVA, D., REQUEIJO, P. \& PADILLA, G. (2017): “Usos y tendencias de Twitter en la campaña a elecciones generales españolas del 20D de 2015: hashtags que fueron trending topic", El profesional de la información, 26 (5), 824-837. DOI: https://doi.org/10.3145/epi.2017.sep.05.

LEE, S. (2016): “How can companies succeed in forming CSR reputation?", Corporate Communications: An International Journal, 21 (4), 435-449.

D0I: https://www.doi.org/10.1108/CCIJ-01-2016-0009.

LÓPEZ, E., ARCAS, N. \& ALCÓN, F. (2014): “Uso y calidad de los sitios web: evaluación en las empresas agroalimentarias murcianas", Revista Española de Estudios Agrosociales y Pesqueros, 237, 155-179. DOI: 10.22004/ag.econ.187489.

LOSADA, C. \& MARUNY, F. (1981): Marketing para cooperativas, Ediciones CEAC, Barcelona.

MARCUELLO, C. \& SANZ, M.I. (2008): "Los principios cooperativos facilitadores de la innovación: un modelo teórico", REVESCO. Revista de Estudios Cooperativos, 94, 59-79.

MARÍN, P.P. \& LASSO DE LA VEGA, M.C. (2017): "La efectividad de las páginas web en la comunicación empresarial de las pequeñas y medianas empresas. Un estudio en PYMES de la provincia de Cádiz", Zer-Revista de estudios de comunicación, 22 (42). DOI: 10.1387/zer.17797.

MARÍN, P.P., LASSO DE LA VEGA, C. \& MIER-TERÁN, J.J. (2015): "La interactividad de las webs en las pequeñas y medianas empresas", Revista Opción, 31.

MARTÍNEZ, A.M., SEGARRA, J. \& MONSERRAT, J. (2018): “Los millennials como prosumers y adprosumers en las redes sociales corporativas, Cuadernos.info, 43, 137-159.

DOI: https://doi.org/10.7764/cdi.43.1335.

MILOJEVIC, A., KLEUT, J. \& NINKOVIC, D. (2013): “Propuestas metodológicas para el estudio de la interactividad en revistas de comunicación", Comunicar, 41, 93-103.

DOI: https://doi.org/10.3916/C41-2013-09.

MONZÓN, J.L. \& CHAVES, R. (2017): Evolución reciente de la economía social en la Unión Europea, Comité Económico y Social Europeo: Bruselas. 
MORENO, A., MOLLEDA, J.C., ATHAYDES, A. \& SUÁREZ, A.M. (2015): Latin American Communication Monitor 2015: Excelencia en comunicación estratégica, trabajo en la era digital, social media y profesionalización. Resultados de una encuesta en 18 países, EUPRERA, Brussels.

MORENO, Á., MOLLEDA, J.C., ATHAYDES, A., SUÁREZ, A.M., HERRERA, M. \& ÁLVAREZ, A. (2017): Latin American Communication Monitor 2016 - 2017. Tendencias en comunicación estratégica: big data, automatization, engagement, influencers, coaching y competencias. Resultados de una encuesta en 17 países, EUPRERA, Brussels.

MORENO, A., MOLLEDA, J.C., ÁLVAREZ, A., HERRERA, M.V., ATHAYDES, A. \& SUÁREZ, A.M. (2019): Comunicación estratégica y sus retos: fake news, confianza, información para la toma de decisiones, liderazgo y compromiso laboral. Resultados de una encuesta en 19 países, EUPRERA. Brussels.

MUÑOZ, R. \& TIRADO, P. (2014): "Responsabilidad social y transparencia a través de la web: un análisis aplicado a las cooperativas agroalimentarias españolas", REVESCO, Revista de Estudios Cooperativos, 114, 84-105. D0I: https://doi.org/10.5209/rev_REVE.2014.v114.44293.

PANIAGUA, F.J. \& GÓMEZ, B.J. (2012): “Hacia la comunicación 2.0. el uso de las redes sociales por parte de las Universidades españolas", Icono 14, 10 (3).

D0I: https://doi.org/10.7195/ri14.v10i3.473

PÉREZ, R. \& LUQUE, S. (2018): “El marketing de influencia en moda. Estudio del nuevo modelo de consumo en Instagram de los millennials universitarios", adComunica, Revista de Estrategias, Tendencias e Innovación en Comunicación, 15.

D0I: http://dx.doi.org/10.6035/2174-0992.2018.15.13.

PÉREZ, M. \& NICASIO, B. (2015): “Campañas 2.0 en la Comunidad Valenciana: las primarias en Coalició Compromís y Ciudadanos como estudio de caso", Ámbitos, Revista internacional de comunicación, 29.

PUENTES, R. \& VELASCO, Mạ.M. (2009): “Importancia de las sociedades cooperativas como medio para contribuir al desarrollo económico, social y medioambiental, de forma sostenible y responsable", REVESCO, Revista de Estudios Cooperativos, 99, 104-129.

RODRÍGUEZ, R. \& UREÑA, D. (2011): "Diez razones para el uso de Twitter como herramienta en la comunicación política y electoral", Comunicación y pluralismo, 10, 89-116.

ROMÁN, Y (2016): Análisis de las estrategias de comunicación de las startups españolas. Estudio de casos, tesis doctoral.

SÁ, J. de (2012): "Las prácticas de gestión de marketing en las cooperativas portuguesas", CIRIEC-España, Revista de Economía Pública, Social y Cooperativa, 76, 199-227. 
SÁNCHEZ, M. \& PANIAGUA, F. J. (2013: "Estrategias de comunicación 2.0 en asociaciones profesionales. Estudio del caso de los Colegios Oficiales de Médicos en España", Revista Mediterránea de Comunicación, 4 (1), 21-51. DOI: https://doi.org/10.14198/MEDC0M2013.4.1.02.

SANCHIS, J.R., CAMPOS, V. \& MOHEDANO, A. (2015): “Factores clave en la creación y desarrollo de cooperativas. Estudio empírico aplicado a la Comunidad Valenciana", REVESCO. Revista de Estudios Cooperativos, 119, 183-207. D0I: 10.5209/rev_REVE.2015.n119.49153.

SEITEL, F. (2002): Teoría y práctica de las relaciones públicas, Prentice Hall, Madrid.

SOLER, P. (2001): Investigación de mercados, Servicio de publicaciones de la Universidad Autónoma de Barcelona, Barcelona.

STANTON, N. (1989): Las técnicas de comunicación en la empresa, Ediciones Deusto, Bilbao.

STELZNER, M. (2019): Social Media Marketing Industry Report, SocialMedia, San Diego.

TÚÑEZ, M., COSTA, C. \& MÍGUEZ, M. I. (2018): "Avances y retos de la gestión de la comunicación en el siglo XXI. Procesos, necesidades y carencias en el ámbito institucional", Estudios sobre el Mensaje Periodístico, 24 (1), 921-940. DOI: https://doi.org/10.5209/ESMP.59987

TÚÑEZ, M., MARTÍNEZ, Y. \& ABEJÓN, P. (2010): “Nuevos entornos, nuevas demandas, nuevos periodistas", Estudios sobre el Mensaje Periodístico, 79, 79-94.

VÁZQUEZ, T. (2010): "Servicios de Internet para las empresas oleícolas. La tienda virtual", Revista de Estudios Empresariales, 1, 169-188.

WRIGHT, D.K. \& HINSON, M. (2017): "Tracking How Social and Other Digital Media are Being Used in Public Relations Practice: A Twelve-Year Study", Public Relations Journal, 11 (1).

ZERFASS, A., MORENO, Á., TENCH, R., VERČIČ, D. \& VERHOEVEN, P. (2017): European Communication Monitor 2017. How strategic communication deals with the challenges of visualisation, social bots and hypermodernity. Results of a survey in 50 Countries, EACD/EUPRERA, Quadriga Media Berlin, Brussels.

ZUGASTI, R. \& SABÉS, F. (2015): “Los issues de los candidatos en Twitter durante la campaña de las elecciones generales de 2011", Zer, 20 (38), 161-178. 
